\title{
Second-Order Fast Terminal Sliding Mode Control for MPPT of PMSG-based Wind Energy Conversion System
}

\author{
Emre Hasan Dursun*, Ahmet Afsin Kulaksiz \\ Department of Electrical \& Electronics Engineering, Faculty of Engineering and Natural Sciences, \\ Konya Technical University, \\ Konya, Turkey \\ ehdursun@ktun.edu.tr
}

\begin{abstract}
This article proposes a new maximum power point tracking (MPPT) controller based on voltage-mode Second-Order Fast Terminal Sliding Mode Control (SOFTSMC) to obtain better performance in the power extraction from Permanent Magnet Synchronous Generator (PMSG)based Wind Energy Conversion System (WECS). The major objective of the study is the design of SO-FTSMC that can ensure the operation of the system in maximum power reference with higher efficiency, less steady-state error, and voltage fluctuation. Maximum power references are determined by mechanical sensorless MPPT approach. The small-scale WECS configuration incorporates wind turbine, PMSG, uncontrolled rectifier, boost converter, and MPPT controller. SO-FTSMC method has not been performed before as a voltage regulator in such a topology. The proposed controller has been validated for two different wind speed test scenarios in simulation environment, which can be applied effectively to PMSG-based WECS. Moreover, Conventional SMC (C-SMC) is created and then performance of controllers is compared in these wind speed scenarios according to maximum extracted average power, output voltage fluctuation, and voltage error in steady-state, MPPT efficiency, and performance indices. Obtained results indicate that proposed SO-FTSMC-based MPPT controller achieves superior performance.
\end{abstract}

Index Terms-Maximum power point tracking; PMSG; Second-order fast terminal SMC; Voltage regulator; WECS.

\section{INTRODUCTION}

The continuous increase of the world population and technological developments constantly boosts the energy demand of countries. The energy generation with conventional fuels raises serious concerns, such as lack of resources and global warming [1], [2]. However, the share of renewable energy sources in energy generation has been growing particularly in the last 10 years. Among them, as a clean and endless energy source, wind energy has one of the best application potentials in the market [3]. Considering financial investments and technological developments, wind energy is expected to become an even more economical

Manuscript received December 30, 2019; accepted 29 May, 2020.

The research for this paper was financially supported by Scientific Research Projects' Coordinatorship of Konya Technical University. We also would like to thank the Scientific and Technological Research Council of Turkey (TUBITAK) BIDEB-2211/C. energy source in the future.

In the wind energy industry, it is expected that Wind Energy Conversion Systems (WECSs) harvest maximum power from the energy of the wind with minimal expenses. Even if WECS can be operated both at constant speed and variable speed with appropriate configurations [4], when it comes to efficiency, the maximization of the power to be captured from the wind at any time can only be achieved via searching of maximum power point (MPP) in variable speed WECS (VS-WECS) configuration. Moreover, VS-WECSs are more preferred because they can be operated at a broad speed range. In the VS-WECS configuration, various generators, such as Doubly-Fed Induction Generators (DFIG) and Permanent Magnet Synchronous Generators (PMSG) are employed. Nevertheless, PMSGs have undergone significant developments recently and are widely preferred for their advantages like lightweight, low noise, high power density, efficiency, low maintenance cost, and gearless operation [5]-[7]. Therefore, the authors practice on PMSG-based VS-WECS in this paper.

While it can be seen that different types of power conversion topologies are used in industrial applications and research studies, since especially small and medium-sized applications are evaluated in terms of efficiency and cost, the topology preferred in this study consists of uncontrolled rectifier, DC-DC boost converter (BC).

Wind speed is in a time-varying form and includes high nonlinearity. Therefore, an effective Maximum Power Point Tracking (MPPT) control scheme is also required to contribute to the overall efficiency of WECS [8]. MPPT operation for WECS can be implemented via different approaches similar to Photovoltaic (PV) and is examined by the researchers in two main parts. These are MPPT search methods and controller designs that will bring the generator to the optimum operating point by switching the power converter. Both parts are very important because they affect efficiency and performance and the subject of the controller design is the main theme of this study.

Recently, it is seen that different methods on the control of WECS have been used in literature. As a widely adopted and simple to design linear control method, proportional integral derivative (PID) controller has been extensively 
used in previous years. However, later, the usage of intelligent control methods has been investigated as PID structures often fail to provide sufficient performance. At this point, fuzzy logic control (FLC) [9], radial basis function neural network (RBF-NN), and reinforcement learning-based different artificial neural network (ANN) structures [10], [11] are utilized. On the other hand, there are some disadvantages, such as learning time, processing load, and prior knowledge requirement. In addition to these methods, back-stepping approach [12] and different sliding mode techniques [13]-[17], which are nonlinear control methods, are encountered in the literature. The main theme of this study is realized on the basis of sliding mode control (SMC).

As a robust nonlinear control scheme, SMC exhibits low sensitivity to disturbing effects and parametric changes [18], [19]. Moreover, it can be put into practice easily to ensure performance increase to WECS. In [13], integral SMC (ISMC) approach is presented to track the optimal voltage detected by FLC. In [14], Discrete-time I-SMC is adopted to produce the switching signal of the BC for tracking MPPT reference in the capturing maximum power from PMSGbased WECS. In [15], the authors propose the second-order fast terminal SMC (SO-FTSMC) as a generator speed controller for MPPT. In [16], the Recurrent NN based on adaptive I-SMC method is employed to ensure the maximum power extraction by tracking optimal turbine speed. On the other hand, sliding mode extremum seeking control approach is presented for MPPT searching in [17].

In the Conventional SMC (C-SMC), steady-state error and high chattering may occur depending on the operating conditions. Furthermore, sliding surface of C-SMC is linear and asymptotic stability can be achieved when the system states are in the sliding mode, but the convergence of the error signal to zero may not be ensured in finite-time [20], [21]. Thus, the terminal SMC (T-SMC) with a nonlinear sliding surface has been proposed for converging in finitetime. Nevertheless, as long as states of the system move away from the equilibrium, convergence problem may occur [22]. In addition, an intrinsic singular problem eventuates in most cases as a result of its fractional function structure as a sliding hyperplane [20]. For these reasons, fast terminal SMC (FT-SMC) has been proposed [22], [23]. On the other hand, high-order SMC (HO-SMC), which includes secondorder SMC (SO-SMC), is known as another effective control scheme [24]. Also, SO-SMC is a new and effectual scheme to avoid chattering problem and can offer a smooth control with better performance while maintaining robustness [25].

In the literature studies examined, it is seen that various SMC-based approaches have been discussed. Motivated by the above investigation, the authors have designed the SOFTSMC as a voltage regulator for generating the control signal to bring the system to optimal voltage to provide MPPT. Thus, superior efficiency can be achieved by providing faster convergence and better tracking performance. In PMSG-based WECS configuration consisting of uncontrolled rectifier and $\mathrm{BC}$, which is shown in Fig. 1, voltage-mode SO-FTSMC structure as a voltage regulator has not been used before.

The organization of the rest of the article is as follows. Section II provides the introduction of PMSG-based WECS configuration. In Section III, the proposed MPPT controller design is presented in detail. In Section IV, the simulation studies and validations are provided and discussed. Finally, conclusions are drawn in Section V.

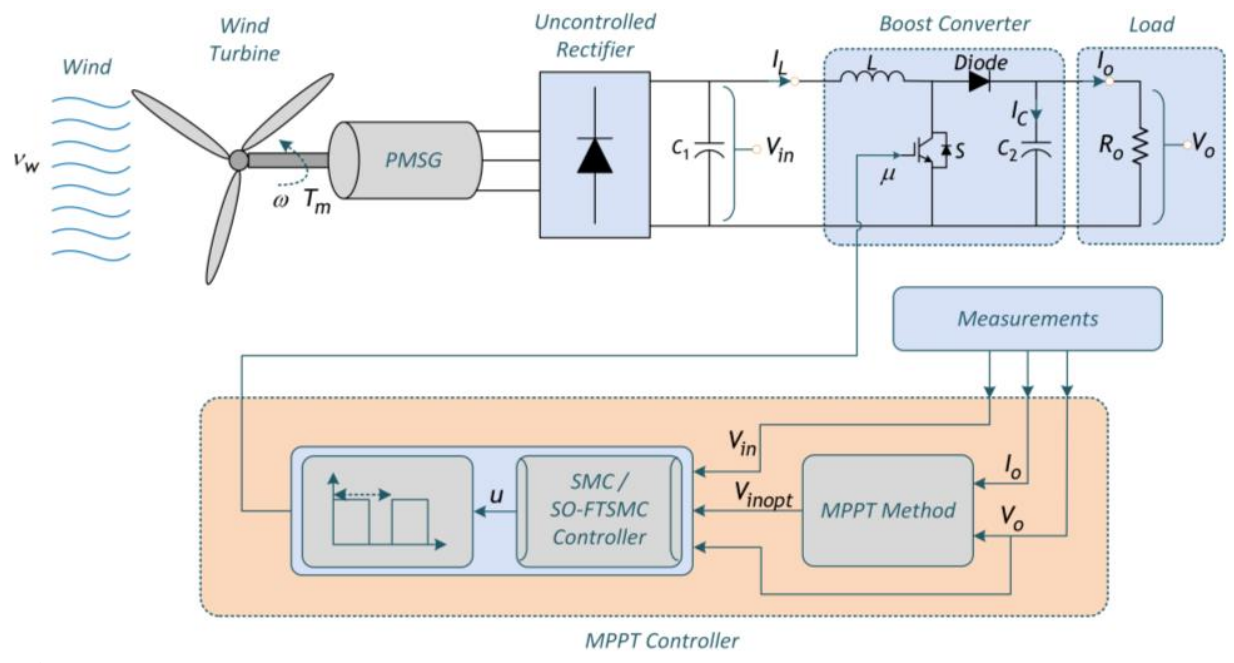

Fig. 1. WECS configuration.

\section{PMSG-BASED WECS CONFIGURATION}

Small-scale PMSG-based WECS configuration consists of wind turbine, PMSG, uncontrolled rectifier, boost converter (BC), and controller. The output of PMSG directly connected to turbine shaft is transferred to three phase uncontrolled rectifier and to the load via BC [26]. Here, MPPT is operated by performing some measurements to obtain optimal value and the determined point is transferred to the controller. The controller generates the switching signal of the BC to regulate the PMSG voltage. In this way, maximum power extraction from WECS is fulfilled.

The mechanical power output captured from the wind turbine can be expressed as

$$
P_{m}=\frac{1}{2} \rho A C_{p}(\lambda, \beta) v_{w}{ }^{3},
$$


where $v_{w}$ is the wind speed, $\rho$ is air density, $A$ is swept area of WT, and $C_{P}(\lambda, \beta)$ is the power coefficient of WT, which comprises of $\lambda$ and $\beta$. In addition, $C_{P}(\lambda, \beta)$ can be defined as:

$$
\left\{\begin{array}{l}
C_{p}(\lambda, \beta)=C_{1}\left(\frac{C_{2}}{\lambda_{i}}-C_{3} \beta-C_{4}\right) e^{-\left(C_{5} / \lambda_{i}\right)}+C_{6} \lambda, \\
\frac{1}{\lambda_{i}}=\frac{1}{\lambda+0.08 \beta}-\frac{0.035}{\beta^{3}+1},
\end{array}\right.
$$

where $C_{1}-C_{6}$ are used as $0.5176,116,0.4,5,21$, and 0.0068 , respectively. $C_{P}$ only depends on $\lambda$ in the WT with fixed pitch angle $(\beta=0)$, which is as follows

$$
\lambda=\frac{\omega_{m} R}{v_{w}}
$$

where $R$ and $\omega_{m}$ are radius and rotational speed of blades, respectively.

$$
\begin{aligned}
& \text { If } v_{w} \text { and } A=\pi R^{2} \text { are replaced into (1), } P_{m_{-} \max } \text { is as } \\
& \qquad P_{m_{-} \max }=\frac{1}{2} \frac{\rho \pi R^{5} C_{p \max }}{\lambda_{\text {opt }}{ }^{3}} \omega_{m}{ }^{3}=K_{p_{-} \text {opt }} \omega_{m}{ }^{3},
\end{aligned}
$$

where $K_{p_{-} o p t}$ is a constant. However, the captured mechanical power is converted to electrical energy through the generator and transferred to the load via BC. Herein, there are losses in the generator and power converter topology, which are not constant. Therefore, more accurate and effective results can be obtained if MPPT is evaluated on the load-side for maximum electrical power consumption on the load during operation.

The electrical power delivered to the load is given as follows

$$
P_{L}=\eta_{g e n} \eta_{c o n v} P_{m}
$$

where $\eta_{g e n}$ and $\eta_{\text {conv }}$ indicate efficiency of generator and converter, respectively. Induced back emf of PMSG is defined as

$$
E=k p \omega_{m}
$$

where $k$ is a constant, $p$ is the number of the pole pairs, and $\omega_{m}$ is the rotor speed. Then, one phase voltage of PMSG is defined in the steady-state as

$$
V=E-I\left(R_{s}+j p \omega_{m} L_{s}\right)
$$

where $R_{s}$ and $L_{s}$ are stator phase resistance and inductance, respectively, and $I$ is the phase current. Neglecting the diode losses and rearranging the equations, output voltage of rectifier is obtained as

$$
V_{d c}=\frac{3 \sqrt{6}}{\pi}\left(\sqrt{\left(k p \omega_{m}\right)^{2}-\left(p \omega_{m} L_{s} I\right)^{2}}-I R_{s}\right)-\frac{3}{\sqrt{6}} p \omega_{m} L_{s} I
$$

As can be seen here, ignoring the convergence at low power, the linearity between $V_{d c}$ and $\omega_{m}$ can be written as

$$
V_{d c}=k_{V} \omega_{m}
$$

where $k_{v}$ is an approximation constant.

\section{PROPOSED MPPT CONTROLLER}

This section covers detailed design of the proposed MPPT controller, and block diagram of the SO-FTSMC-based MPPT controller for WECS is demonstrated in Fig. 2. As can be seen, the optimal operation point is determined by MPPT method and system control is carried out by generating the appropriate switching signal via the SOFTSMC.

\section{A. MPPT Method}

Researchers have reported numerous MPPT methods in literature. They have advantages and disadvantages against each other in different directions, such as the need for prior knowledge, learning, and processing load, cost and convergence speed [5], [27]. Herein, PSF method, which can perform quite well in cases where the aerodynamic characteristics of WT are known, is employed in this study.

The relation between output power $P_{L_{-} \max }$ and $V_{d c}$ can be written as follows

$$
\begin{aligned}
& P_{L_{-} \max }=\eta_{g e n} \eta_{\text {conv }} P_{m}=\eta_{g e n} \eta_{\text {conv }} K_{p_{-} o p t} \omega_{m}^{3}= \\
& =\eta_{\text {gen }} \eta_{\text {conv }} K_{p_{-} \text {opt }} \frac{V_{d c_{-} o p t}}{k_{v}{ }^{3}}=K_{r_{-} o p t} V_{d c_{-} o p t}{ }^{3},
\end{aligned}
$$

where $K_{r_{-} \text {opt }}$ is optimal voltage constant, $P_{L_{-} \max }$ is related to $V_{d c_{-} o p t}$. In this way, without any mechanical wind speed sensor, maximum available power can be extracted by tracking $V_{d c}$ reference at $V_{d c_{-} o p t}$. $K_{r_{-} o p t}$ values for each wind speed can be obtained from simulation tests and validations [27].

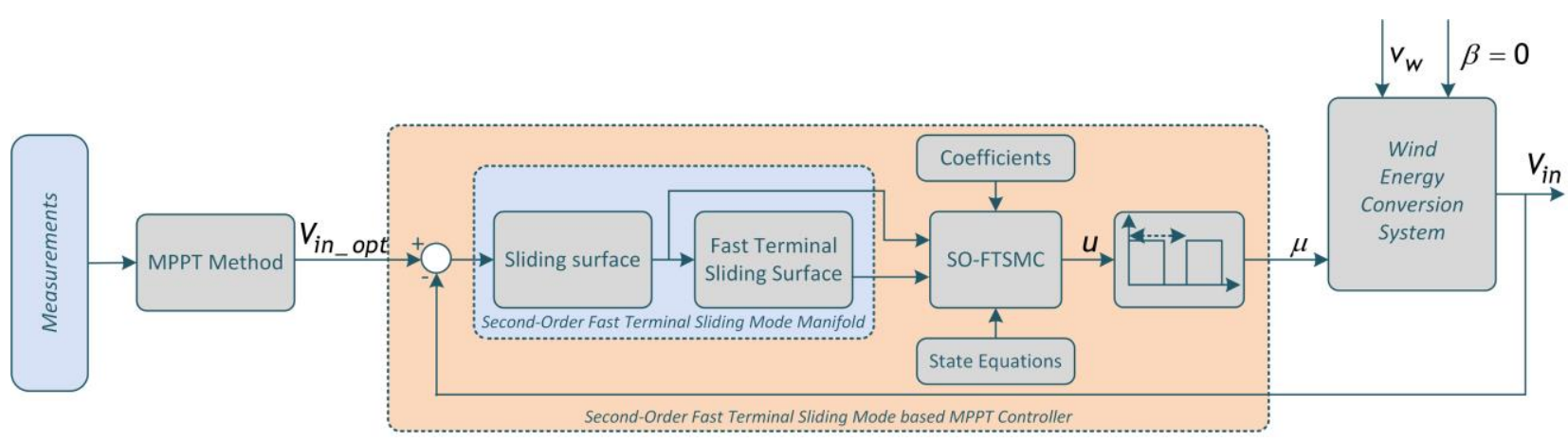

Fig. 2. Block diagram of Second-Order Fast Terminal Sliding Mode-Based MPPT Controller for WECS. 


\section{B. Controller Design}

Dynamics of $\mathrm{BC}$ are given as below:

$$
\left\{\begin{array}{l}
\frac{d V_{o}}{d t}=\bar{u} \frac{I_{L}}{C}-\frac{V_{o}}{R C}, \\
\frac{d I_{L}}{d t}=-\bar{u} \frac{V_{o}}{L}+\frac{V_{i n}}{L}, \\
I_{C}=\bar{u} I_{L}-\frac{V_{o}}{R}, \\
V_{\text {in }}=\kappa V_{o},\{\kappa=1-d\},
\end{array}\right.
$$

where $R, C$, and $L$ symbolize load resistance, capacitance, and inductance, respectively. Also, $V_{i n}, V_{o}, I_{L}$, and $I_{C}$ are input and output voltages, and inductor and capacitor currents, respectively. $\bar{u}=1-u$ is inverse control signal and $\kappa$ is converter ratio.

The system variables to be controlled can be defined as:

$$
\left\{\begin{array}{l}
X_{1}=V_{i n_{1} o p t}-V_{i n}, \\
X_{2}=\kappa\left(\frac{V_{o}}{R C}+\int \bar{u} \frac{V_{o}-V_{i n}}{L C} d t\right), \\
\dot{X}_{2}=-\frac{X_{2}}{R C}+\bar{u} \kappa\left(\frac{V_{o}-V_{i n_{-} o p t}+X_{1}}{L C}\right) .
\end{array}\right.
$$

The first step of the controller design is initiated by creating sliding surface, and linear sliding surface is

$$
s(t)=\lambda_{C} X_{1}+X_{2},
$$

where $\lambda_{C}$ expresses slope of the surface. Then, this linear surface is modified as follows

$$
\dot{s}(t)+\gamma s(t)=k_{p} X_{1}+k_{i} \int_{0}^{t} X_{1}(\tau) d \tau+k_{d} \dot{X}_{1},
$$

where $k_{p}, k_{i}$, and $k_{d}$ are independent coefficients of PID surface. Later, the fast terminal manifold is designed with the second-order concept to guarantee convergence of $s(t)$ in finite-time and to reduce chattering, which is as follows

$$
\sigma=\dot{s}(t)+\beta_{1} s(t)+\beta_{2} s(t)^{p / q},
$$

where $\sigma \in R, p$, and $q$ are positive odd integer and $0.5<p / q<1$. Derivative on both sides of (15) with respect to time is

$$
\begin{aligned}
\dot{\sigma} & =\ddot{s}(t)+\beta_{1} \dot{s}(t)+\beta_{2} \frac{p}{q} s(t)^{p / q-1} \dot{s}(t)= \\
& =\ddot{s}(t)+\dot{s}(t)\left(\beta_{1}+\beta_{2} \frac{p}{q} s(t)^{p / q-1}\right) .
\end{aligned}
$$

Thereafter, taking derivate of (14) with respect to time and substituting it into (16) gives

$$
\begin{aligned}
& \dot{\sigma}=K_{p} \dot{X}_{1}+K_{i} X_{1}+K_{d} \ddot{X}_{1}+ \\
& +\dot{s}(t) \overbrace{\left(-\gamma+\beta_{1}+\beta_{2} \frac{p}{q} s(t)^{p / q-1}\right)} .
\end{aligned}
$$

And taking derivate of (13) with respect to time and substituting it into (17) gives

$$
\begin{aligned}
\dot{\sigma} & =K_{p} \dot{X}_{1}+K_{i} X_{1}+K_{d} \ddot{X}_{1}+\left(\lambda_{C} \dot{X}_{1}+\dot{X}_{2}\right) \vartheta= \\
& =\dot{X}_{1}\left(K_{p}+\lambda_{C} \vartheta\right)+K_{i} X_{1}+\dot{X}_{2}\left(K_{d}+\vartheta\right) .
\end{aligned}
$$

In addition, replacing the state equations in (12) into (18), $\dot{\sigma}$ is synthesized as below

$$
\begin{gathered}
\dot{\sigma}=\left(K_{p}+\lambda_{C} \vartheta-\frac{K_{d}+\vartheta}{R C}\right) X_{2}+K_{i} X_{1}+ \\
+\bar{u} \kappa\left(K_{d}+\vartheta\right)\left(\frac{V_{o}-V_{\text {in_opt }}+X_{1}}{L C}\right)=0 .
\end{gathered}
$$

From here, by obtaining $\bar{u}$ inverse control signal, $u$ control signal is arranged from $u=1-\bar{u}$ as follows

$$
\begin{aligned}
& u=1+\frac{1}{\kappa\left(K_{d}+\vartheta\right)}\left(\frac{L C}{V_{o}-V_{i n_{-} o p t}+X_{1}}\right) \times \\
& \times\left(\left(K_{p}+\lambda_{C} \vartheta-\frac{K_{d}+\vartheta}{R C}\right) X_{2}+K_{i} X_{1}\right) .
\end{aligned}
$$

\section{Simulation StUdies AND VAlidations}

WECS configuration presented in Fig. 1 is designed by modelling in a simulation environment and all designs and tests have been performed and verified here. In this section, for harvesting maximum power from PMSG-based WECS, the performance of the voltage-mode SO-FTSMC and CSMC structures designed as a voltage regulator is tested and compared with each other. Specific data for PMSG and BC are given in Table I.

Herein, two different wind speed scenarios having step variations and realistic variations are created for the range from $6 \mathrm{~m} / \mathrm{s}$ to $12 \mathrm{~m} / \mathrm{s}$. Performance of controllers is assessed for the scenarios according to some specific criteria, namely, MPPT efficiency, maximum extracted average power, and voltage error in steady-state, output voltage ripple, and performance indices.

TABLE I. CONFIGURATION PARAMETERS OF THE WECS.

\begin{tabular}{|c|c|c|c|}
\hline \multicolumn{2}{|c|}{ PMSG Parameters } & \multicolumn{2}{c|}{ BC Parameters } \\
\hline Definition & Value & Definition & Value \\
\hline Rotor type & Salient-pole & Switching frequency, $f_{s w}$ & $5 \mathrm{kHz}$ \\
\hline Phase number & 3 & Inductor, $L$ & $310 \mu \mathrm{H}$ \\
\hline $\begin{array}{c}\text { Stator phase } \\
\text { resistance }\end{array}$ & $1 \Omega$ & Capacitor, $C$ & $240 \mu \mathrm{F}$ \\
\hline $\begin{array}{c}\text { Armature } \\
\text { inductance } L_{d}, \\
L_{q}\end{array}$ & $0.00153 \mathrm{H}$ & Inductor resistance, $R_{L}$ & $0.15 \Omega$ \\
\hline $\begin{array}{c}\text { Inertia, } J \\
\text { Viscous } \\
\text { damping, } F\end{array}$ & $0.013 \mathrm{~kg} . \mathrm{m}^{2}$ & Capacitor ESR, $R_{C}$ & $0.07 \Omega$ \\
\hline $\begin{array}{c}\text { Pole pairs } \\
\text { number, } n_{p}\end{array}$ & 16 & Load resistance, $R$ & $36 \Omega$ \\
\hline
\end{tabular}

\section{A. Test Scenario I}

For the first test scenario, the wind speed profile having step variations between $6 \mathrm{~m} / \mathrm{s}$ to $12 \mathrm{~m} / \mathrm{s}$ is formed as depicted in Fig. 3. In this wind profile, change of output 
extracted power is shown in Fig. 4. In addition, for better visibility, change in $3^{\text {rd }}$ second is presented by zooming in here. It can be understood that a higher power is obtained with less fluctuation and closer tracking to optimal power by the SO-FTSMC method. Moreover, the obtained power data for each wind speed in this scenario are listed in Table II. Herein, efficiency for both controllers is also compared in terms of average extracted output power in steady-state.

In this respect, the change of the $\mathrm{BC}$ output voltage transferred to load for accomplishing MPPT is indicated in
Fig. 5. Herein, it is seen that SO-FTSMC voltage controller tracks to MPP reference with less steady-state error and fluctuation. On the other hand, change of output voltage error is presented in Fig. 6 and the result of the proposed method is closer to zero. Meanwhile, voltage ripples and steady-state errors for each wind speed are given in Table III. Also, Table IV presents the obtained results by using IAE, ISE, and ITAE performance indices as another comparison criterion. According to this table, it is clearly seen that the proposed controller is superior.

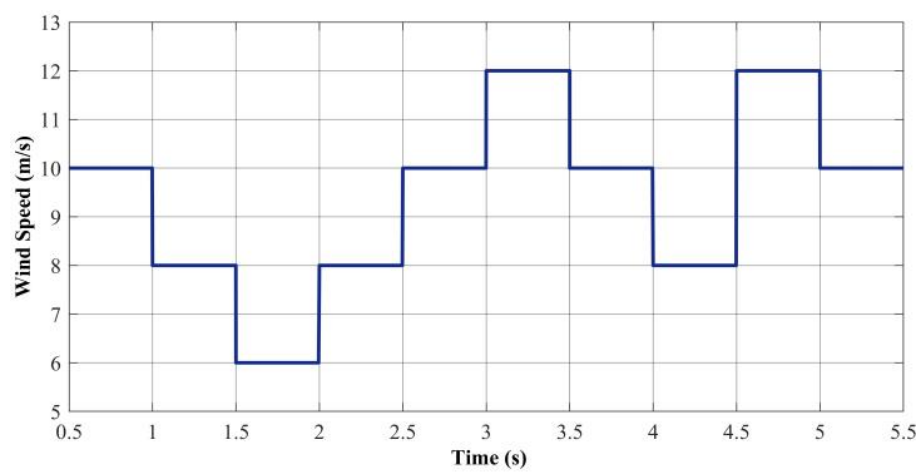

Fig. 3. Step change wind speed profile.

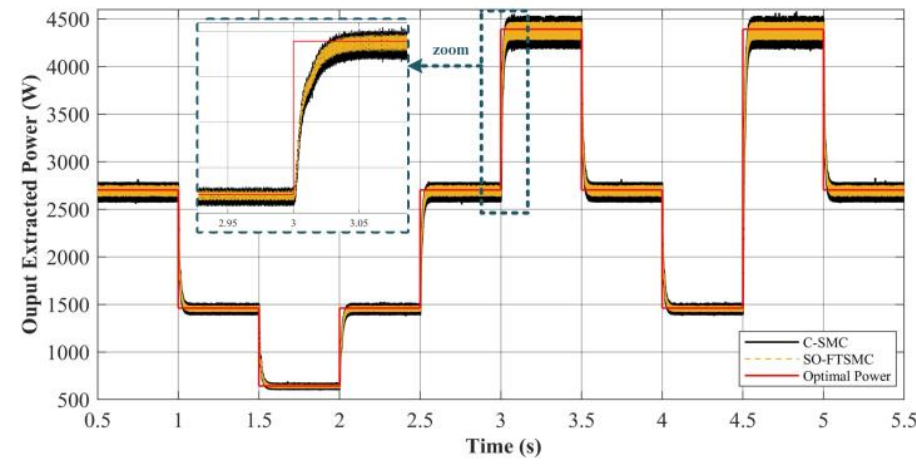

Fig. 4. Output power extracted from WECS for test scenario I.

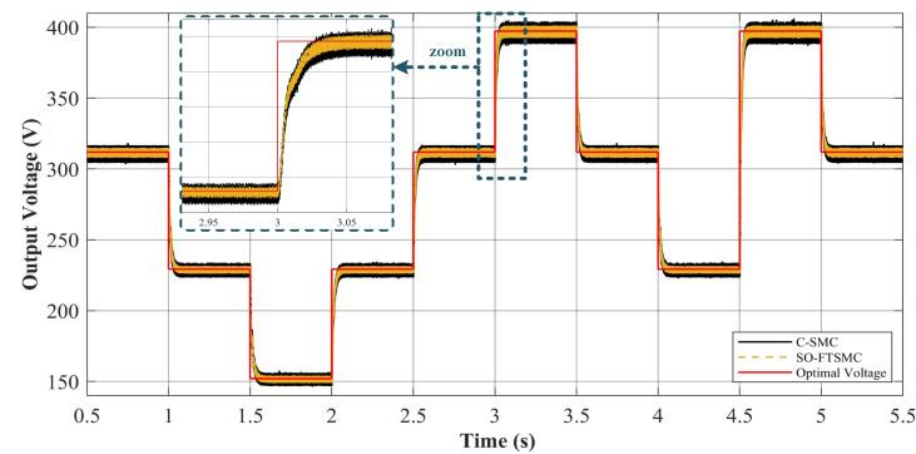

Fig. 5. Change of output voltage for test scenario I.

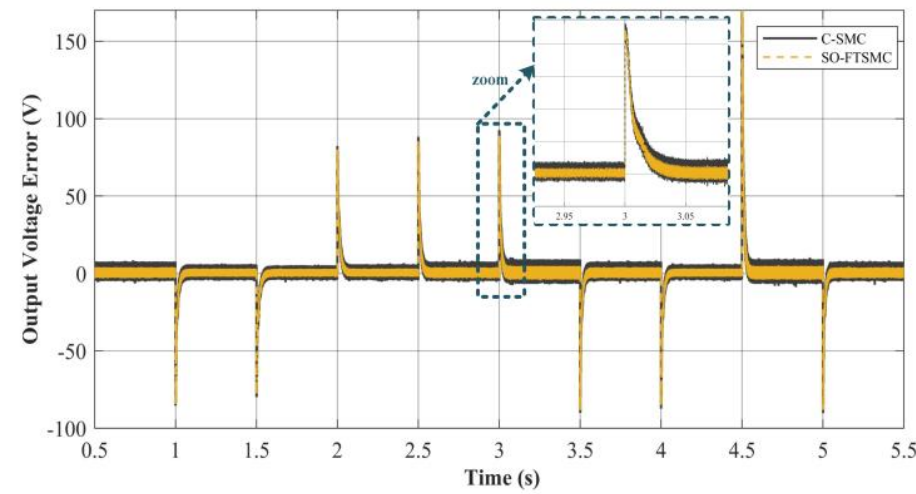

Fig. 6. Output voltage error for test scenario I. 
TABLE II. POWER AND EFFICIENCY COMPARISON OF CONTROLLERS.

\begin{tabular}{|c|c|c|c|c|c|}
\hline \multirow{2}{*}{$\begin{array}{c}\mathbf{V}_{\boldsymbol{w}} \\
(\boldsymbol{m} / \boldsymbol{s})\end{array}$} & \multirow{2}{*}{$\begin{array}{c}\text { Available } \\
\boldsymbol{P}_{\max }(\boldsymbol{W})\end{array}$} & \multicolumn{2}{|c|}{ Average Power $\boldsymbol{W})$} & \multicolumn{2}{c|}{ Efficiency \% } \\
\cline { 3 - 6 } & & $C$-SMC & $\begin{array}{c}S O- \\
F T S M C\end{array}$ & $C$-SMC & $\begin{array}{c}\text { SO- } \\
F T S M C\end{array}$ \\
\hline 6 & 643 & 637 & $\mathbf{6 4 0}$ & 99.067 & $\mathbf{9 9 . 5 3 3}$ \\
\hline 8 & 1461 & 1451 & $\mathbf{1 4 5 7}$ & 99.316 & $\mathbf{9 9 . 7 2 6}$ \\
\hline 10 & 2703 & 2682 & $\mathbf{2 6 9 9}$ & 99.223 & $\mathbf{9 9 . 8 5 2}$ \\
\hline 12 & 4392 & 4357 & $\mathbf{4 3 8 5}$ & 99.203 & $\mathbf{9 9 . 8 4 1}$ \\
\hline
\end{tabular}

TABLE III. VOLTAGE COMPARISON OF CONTROLLERS.

\begin{tabular}{|c|c|c|c|c|}
\hline \multirow{2}{*}{$\begin{array}{c}\mathbf{V}_{\boldsymbol{w}} \\
(\boldsymbol{m} / \mathbf{s})\end{array}$} & \multicolumn{2}{|c|}{ Voltage ripple $(\boldsymbol{V})$} & \multicolumn{2}{|c|}{$\begin{array}{c}\text { Steady-state voltage error } \\
(\boldsymbol{V})\end{array}$} \\
\cline { 2 - 5 } & $C-S M C$ & SO-FTSMC & $C$-SMC & SO-FTSMC \\
\hline 6 & 3.2 & $\mathbf{2}$ & 1.02 & $\mathbf{0 . 2 9}$ \\
\hline 8 & 5 & $\mathbf{2 . 5}$ & 1.29 & $\mathbf{0 . 2 7}$ \\
\hline 10 & 6.4 & $\mathbf{4 . 2}$ & 1.63 & $\mathbf{0 . 1 7}$ \\
\hline 12 & 9.5 & $\mathbf{6 . 1}$ & 1.71 & $\mathbf{0 . 0 3}$ \\
\hline
\end{tabular}

TABLE IV. COMPARISONS OF PERFORMANCE INDICES OF CONTROLLERS.

\begin{tabular}{|c|c|c|c|}
\hline Controller & IAE & ISE & ITAE \\
\hline$C-S M C$ & 11.37 & 41.5 & 36.08 \\
\hline SO-FTSMC & $\mathbf{3 . 5 0 9}$ & $\mathbf{3 . 8 4 8}$ & $\mathbf{1 1 . 3 9}$ \\
\hline
\end{tabular}

\section{B. Test Scenario II}

A realistic wind speed profile that changes strongly in the range from $6 \mathrm{~m} / \mathrm{s}$ to $12 \mathrm{~m} / \mathrm{s}$ is created for the second scenario as shown in Fig. 7.

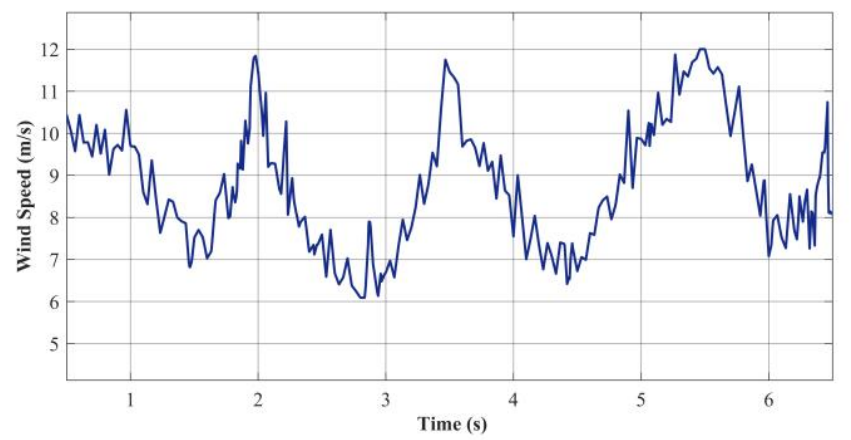

Fig. 7. Realistic wind speed profile.

In this wind speed scenario, changes of the extracted output power and $\mathrm{BC}$ output voltage transferred to load are demonstrated in Fig. 8 and Fig. 9, respectively. As can be seen, SO-FTSMC controller tracks closer to optimal values in power and voltage evaluations. Besides, the data for the extracted average power and efficiency during the simulation period for both controllers are presented in Table V.

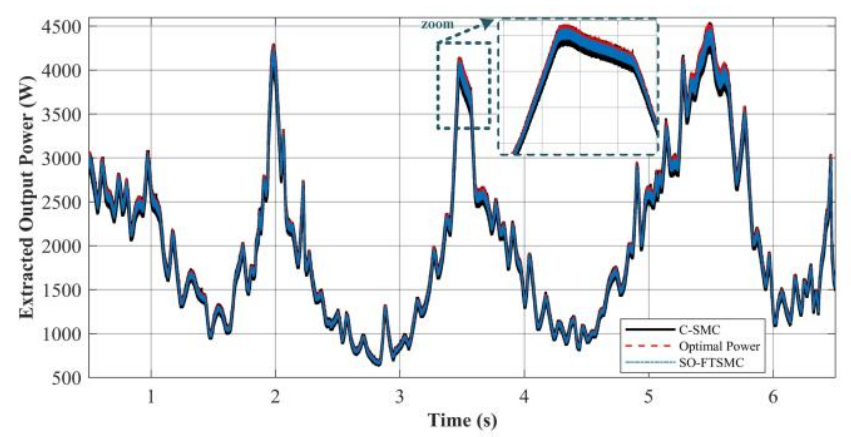

Fig. 8. Extracted output power from WECS for test scenario II.

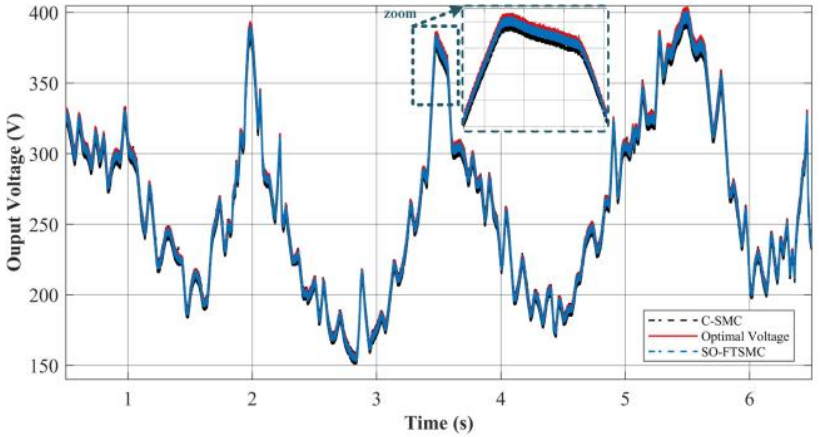

Fig. 9. Change of output voltage for test scenario II.

On the other hand, another comparison is made in terms of performance indices and results are given in Table VI. Similar to previous results, the proposed controller design is operated at a superior performance.

TABLE V. POWER AND EFFICIENCY COMPARISON OF CONTROLLERS

\begin{tabular}{|c|c|c|c|}
\hline Controller & $\begin{array}{c}\text { Efficiency } \\
\boldsymbol{\%}\end{array}$ & $\begin{array}{c}\text { Average } \\
\text { Power }(\boldsymbol{W})\end{array}$ & $\begin{array}{c}\text { Average available } \\
\mathbf{P}_{\text {max }}(\boldsymbol{W})\end{array}$ \\
\hline C-SMC & 99.254 & 1996 & \multirow{2}{*}{$\mathbf{2 0 1 1}$} \\
\hline SO-FTSMC & $\mathbf{9 9 . 8 5 1}$ & $\mathbf{2 0 0 8}$ & \\
\hline
\end{tabular}

TABLE VI. COMPARISONS OF PERFORMANCE INDICES OF CONTROLLERS.

\begin{tabular}{|c|c|c|c|}
\hline Controller & IAE & ISE & ITAE \\
\hline$C-S M C$ & 12.32 & 40.40 & 43.76 \\
\hline$S O-F T S M C$ & $\mathbf{3 . 5 7 5}$ & $\mathbf{3 . 3 4 1}$ & $\mathbf{1 2 . 8 1}$ \\
\hline
\end{tabular}

\section{CONCLUSIONS}

In this study, voltage-mode second-order fast terminal sliding mode control (SO-FTSMC) based MPPT controller is proposed for efficiency improvement of PMSG-based WECS. Herein, reference values of MPPT operation are determined by a mechanical sensorless approach. Thanks to the design of this controller, it is clearly presented that WECS can be operated in MPP reference with higher efficiency, less voltage fluctuation, and steady-state error. Two different test scenarios are created in a simulation environment and the SO-FTSMC-based MPPT controller is tested for these scenarios. Moreover, the C-SMC controller is designed to compare and prove the effectiveness of SOFTSMC. Obtained results are evaluated in terms of different criteria consisting of extracted average output power and efficiency and voltage fluctuation, voltage error in steadystate, and performance indices. They indicate that SOFTSMC-based MPPT controller provides performance improvements.

\section{CONFLICT OF INTEREST}

The authors declare no conflict of interest.

\section{REFERENCES}

[1] C. Cader, P. Bertheau, P. Blechinger, H. Huyskens, and C. Breyer, "Global cost advantages of autonomous solar-battery-diesel systems compared to diesel-only systems", Energy for Sustainable Development, vol. 31, pp. 14-23, 2016. DOI: 10.1016/j.esd.2015.12.007.

[2] H. Matayoshi, A. M. Howlader, M. Datta, and T. Senjyu, "Control strategy of PMSG based wind energy conversion system under strong 
wind conditions", Energy for Sustainable Development, vol. 45, pp. 211-218, 2018. DOI: 10.1016/j.esd.2018.07.001.

[3] C. Huang, F. Li, and Z. Jin, "Maximum power point tracking strategy for large-scale wind generation systems considering wind turbine dynamics", IEEE Transactions on Industrial Electronics, vol. 62, no. 4, pp. 2530-2539, 2015. DOI: 10.1109/TIE.2015.2395384.

[4] A.-R. Youssef, A. I. M. Ali, M. S. R. Saeed, and E. E. M. Mohamed, "Advanced multi-sector $\mathrm{P} \& \mathrm{O}$ maximum power point tracking technique for wind energy conversion system", International Journal of Electrical Power \& Energy Systems, vol. 107, pp. 89-97, 2019. DOI: 10.1016/j.ijepes.2018.10.034.

[5] E. H. Dursun and A. A. Kulaksiz, "Maximum power extraction from PMSG based VS-WECS by using variable Step-Size P\&O Method", in Proc. of 3rd International Symposium on Multidisciplinary Studies and Innovative Technologies (ISMSIT), Ankara, 2019, pp. 15. DOI: 10.1109/ISMSIT.2019.8932841.

[6] A. Bonfiglio, F. Delfino, F. Gonzalez-Longatt, and R. Procopio, "Steady-state assessments of PMSGs in wind generating units", International Journal of Electrical Power \& Energy Systems, vol. 90, pp. 87-93, 2017. DOI: 10.1016/j.ijepes.2017.02.002.

[7] A. Gencer, "Analysis and control of low-voltage ride-through capability improvement for PMSG based on an NPC converter using an interval type-2 fuzzy logic system", Elektronika ir Elektrotechnika, vol. 25, no. 3, pp. 63-70, 2019. DOI: 10.5755/j01.eie.25.3.23678.

[8] J. Chen, W. Yao, C.-K. Zhang, Y. Ren, and L. Jiang, "Design of robust MPPT controller for grid-connected PMSG-based wind turbine via perturbation observation based nonlinear adaptive control", Renewable Energy, vol. 134, pp. 478-495, 2019. DOI: 10.1016/j.renene.2018.11.048.

[9] J. Lee and Y. Kim, "Sensorless fuzzy-logic-based maximum power point tracking control for a small-scale wind power generation systems with a switched-mode rectifier", IET Renewable Power Generation, vol. 10, no. 2, pp. 194-202, 2016. DOI: 10.1049/ietrpg.2015.0250

[10] W.-M. Lin and C.-M. Hong, "Intelligent approach to maximum power point tracking control strategy for variable-speed wind turbine generation system", Energy, vol. 35, no. 6, pp. 2440-2447, 2010. DOI: 10.1016/j.energy.2010.02.033.

[11] C. Wei, Z. Zhang, W. Qiao, and L. Qu, "An adaptive network-based reinforcement learning method for MPPT control of PMSG wind energy conversion systems", IEEE Transactions on Power Electronics, vol. 31, no. 11, pp. 7837-7848, 2016. DOI: 10.1109/TPEL.2016.2514370.

[12] L. Wang, L. Cao, and L. Zhao, "Non-linear tip speed ratio cascade control for variable speed high power wind turbines: A backstepping approach", IET Renewable Power Generation, vol. 12, no. 8, pp. 968-972, 2018. DOI: 10.1049/iet-rpg.2017.0698.

[13] X.-x. Yin, Y.-g. Lin, W. Li, Y.-j. Gu, P.-f. Lei, and H.-w. Liu, "Sliding mode voltage control strategy for capturing maximum wind energy based on fuzzy logic control", International Journal of Electrical Power \& Energy Systems, vol. 70, pp. 45-51, 2015. DOI: 10.1016/j.ijepes.2015.01.029.

[14] I. Yazici and E. K. Yaylaci, "Maximum power point tracking for the permanent magnet synchronous generator-based WECS by using the discrete-time integral sliding mode controller with a chattering-free reaching law", IET Power Electronics, vol. 10, no. 13, pp. 17511758, 2017. DOI: $10.1049 /$ iet-pel.2017.0232.

[15] M. Abolvafaei and S. Ganjefar, "Maximum power extraction from a wind turbine using second-order fast terminal sliding mode control", Renewable Energy, vol. 139, pp. 1437-1446, 2019. DOI: 10.1016/j.renene.2019.03.044

[16] X. Yin, Z. Jiang, and L. Pan, "Recurrent neural network based adaptive integral sliding mode power maximization control for wind power systems", Renewable Energy, vol. 145, pp. 1149-1157, 2020. DOI: 10.1016/j.renene.2018.12.098.

[17] L. Hu, F. Xue, Z. Qin, J. Shi, W. Qiao, W. Yang, and T. Yang, "Sliding mode extremum seeking control based on improved invasive weed optimization for MPPT in wind energy conversion system", Applied Energy, vol. 248, pp. 567-575, 2019. DOI 10.1016/j.apenergy.2019.04.073

[18] V. Utkin, J. Guldner, and J. Shi, Sliding Mode Control in ElectroMechanical Systems. CRC press, 2009.

[19] A. Durdu and E. H. Dursun, "Sliding mode control for position tracking of servo system with a variable loaded DC motor", Elektronika ir Elektrotechnika, vol. 25, no. 4, pp. 8-16, 2019. DOI 10.5755/j01.eie.25.4.23964

[20] C.-S. Chiu, "Derivative and integral terminal sliding mode control for a class of MIMO nonlinear systems", Automatica, vol. 48, no. 2, pp. 316-326, 2012. DOI: 10.1016/j.automatica.2011.08.055.

[21] S. Yu, X. Yu, B. Shirinzadeh, and Z. Man, "Continuous finite-time control for robotic manipulators with terminal sliding mode", Automatica, vol. 41, no. 11, pp. 1957-1964, 2005. DOI 10.1016/j.automatica.2005.07.001

[22] L. Yang and J. Yang, "Nonsingular fast terminal sliding-mode control for nonlinear dynamical systems", International Journal of Robust and Nonlinear Control, vol. 21, no. 16, pp. 1865-1879, 2011. DOI: 10.1002/rnc.1666.

[23] Y. Xinghuo and Z. Man, "Fast terminal sliding-mode control design for nonlinear dynamical systems", IEEE Transactions on Circuits and Systems I: Fundamental Theory and Applications, vol. 49, no. 2, pp. 261-264, 2002. DOI: 10.1109/81.983876.

[24] S. Yi and J. Zhai, "Adaptive second-order fast nonsingular terminal sliding mode control for robotic manipulators", ISA Transactions, vol. 90, pp. 41-51, 2019. DOI: 10.1016/j.isatra.2018.12.046.

[25] L. Qiao and W. Zhang, "Adaptive second-order fast nonsingular terminal sliding mode tracking control for fully actuated autonomous underwater vehicles", IEEE Journal of Oceanic Engineering, vol. 44, no. 2, pp. 363-385, 2019. DOI: 10.1109/JOE.2018.2809018.

[26] K. Kajiwara, H. Tajima, H. Maruta, F. Kurokawa, and I. Colak, "Dynamic characteristics of integral gain changeable digital control DC-DC converter for suppression of output capacitance", International Journal of Renewable Energy Research, vol. 6, no. 1, pp. 237-244, 2016.

[27] S. M. Barakati, M. Kazerani, and J. D. Aplevich, "Maximum power tracking control for a wind turbine system including a matrix converter", IEEE Transactions on Energy Conversion, vol. 24, no. 3 , pp. 705-713, 2009. DOI: 10.1109/TEC.2008.2005316.

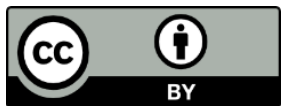

This article is an open access article distributed under the terms and conditions of the Creative Commons Attribution 4.0 (CC BY 4.0) license (http://creativecommons.org/licenses/by/4.0/). 